\title{
Production of polymeric nanofibers with different conditions of the electrospinning process
}

\author{
Bruna da Silva Vaz ${ }^{1}$, Jorge Alberto Vieira Costa ${ }^{2}$ \\ Michele Greque de Morais ${ }^{1}$
}

\author{
${ }^{1}$ Laboratory of Microbiology and Biochemistry, College of Chemistry and Food Engineering, Federal University of Rio \\ Grande, Rio Grande, RS, Brazil \\ e-mail: bruna_vaz_bg@hotmail.com; michele.morais@pq.cnpq.br \\ ${ }^{2}$ Laboratory of Biochemical Engineering, College of Chemistry and Food Engineering, Federal University of Rio \\ Grande, Rio Grande, RS, Brazil \\ e-mail: jorgealbertovc@gmail.com
}

\begin{abstract}
Nanofibers are materials that present high elasticity, strength, porosity and surface-area-to-volume ratio. The electrospinning method is the most widely adopted technique for forming polymeric nanofibers due to repeatability, easy scale-up process and production of long and continuous nanofibers. This method produces nanofibers with diameters ranging from $10 \mathrm{~nm}$ to $1000 \mathrm{~nm}$. The process is regulated by many parameters which significantly affecting the morphology of the nanofibers, and through the proper handling of these parameters are obtained desired nanofibers in morphology and diameters. Based on this, the objective of this work was to evaluate the size and morphology of nanofibers obtained by different conditions of the electrospinning process. The electrospinning technique will be utilized to produce nanofibers with polyacrylonitrile (PAN) polymer and solvent N, N-dimethylformamide (DMF). The polymer solutions $(10 \%$ $(\mathrm{w} / \mathrm{v})$ ) were injected through of the capillary with diameter $0.45 ; 0.55 ; 0.70$ and $0.80 \mathrm{~mm}$. The distances from the collector to the capillary were tested between 100 and $200 \mathrm{~mm}$, voltage between 15 and $25 \mathrm{kV}$, and feed rate of the solution between 100 and $1000 \mu \mathrm{L} / \mathrm{h}$. All of the tests were conducted at $22{ }^{\circ} \mathrm{C}$ with the relative humidity level controlled at $65 \pm 1 \%$. The morphology and size of nanofibers were evaluated by Scanning Electron Microscopy (SEM). Thus, the development of nanofibers with small diameter and high pore volume facilitate bioactive molecules loading and / or transport of nutrients and wastes, and allow the polymeric nanofibers become important class of biomaterials.
\end{abstract}

Keywords: electrospinning, nanotechnology, process parameters.

\section{INTRODUCTION}

Nanotechnology is the science that involves obtaining, manipulation and characterization of functional structures composed of particles with at least one of its dimensions measured in nanometers. On this scale, physical, chemical and biological properties of materials are enhanced by reducing the size that provides greater contact surface and reactivity of the material [1].

Nanotechnology is providing new solutions and opportunities to ensure sustainable energy and environments for the future. Materials of nanofiberous morphology are attractive to solve numerous energy and environmental issues [2], presenting great potential as adsorbents for capture and storage of carbon dioxide $\left(\mathrm{CO}_{2}\right)$ [3]. Polymeric nanofibers have different functionality with respect to their mechanical, electrical and thermal properties, and demonstrate potential for applications in many areas [4].

The electrospinning method is the most widely adopted technique for forming polymer nanofibers due to repeatability, ease of scale-up the process and production of long and continuous nanofibers. This method produces nanofibers ranging from $10 \mathrm{~nm}$ to $1000 \mathrm{~nm}$ in diameter, that present high elasticity, strength and surface area relative to volume, depending on the polymer used [5].

The electrospinning essentially consists of a capillary or a syringe filled containing the polymer solution, a high voltage source and a grounded conductive collector screen. The needle of the syringe typically serves as an electrode to electrically charge the polymer solution and the counter-electrode is connected to the conductive collector screen [6]. 
Electrospinning is carried out by applying a high voltage to a polymer solution in a process that results in nanofiber formation and lengthening due to electrostatic repulsion. The polymer solution is fed at a constant flow rate through a capillary charged with a high voltage $(10 \mathrm{kV}$ to $30 \mathrm{kV})$. When the electric field attains enough energy to overcome surface tension at the tip of the capillary, a "Taylor Cone" forms and the nanofibers are deposited in a stationary or rotating collector where the solvent evaporates and the nanofibers collect [7].

The electrospinning process is conducted by many factors classified in parameters of solution, of the process and environmental. Solution parameters include: polymer concentration; volatile solvent; molecular weight; viscosity; superficial tension and conductivity/surface charge density. Process parameters include electrical potential; flow rate; types of collectors; diameter of the capillary and distance from capillary to the collector. Environmental parameters include: humidity, temperature and air flow.

Each of these parameters significantly affect the fibers morphology obtained as a result of electrospinning, and by proper manipulation of these parameters we can get nanofibers of desired morphology and diameters [8]. Thus, the objective of this work was to evaluate the size and morphology of the nanofibers obtained with different parameters of the electrospinning process.

\section{MATERIALS AND METHODS}

\subsection{Preparation of the polymer solutions}

The polymer utilized was polyacrylonitrile (PAN) of molecular weight 150,000 g/mol (Sigma-Aldrich ${ }^{\circledR}$, United States). The polymer solution of $10 \%(\mathrm{w} / \mathrm{v})$ was prepared with solvent $\mathrm{N}, \mathrm{N}$-dimethylformamide (DMF). The mixture was left under continuous agitation with magnetic stirrer at ambient temperature of $23^{\circ} \mathrm{C}$ for at least 24 hours.

\subsection{Electrospinning}

The electrospinning method was used to produce the polymeric nanofibers. Figure 1 shows a schematic illustration of the basic configuration of the technique. The polymer solution was injected through of the capillary with diameter $0.45 ; 0.55 ; 0.70$ and $0.80 \mathrm{~mm}$. The electric potential was evaluated in 15,20 and $25 \mathrm{kV}$. The distance from the collector to the capillary was fixed in $140 \mathrm{~mm}$ and feed rate of the solution in $500 \mu \mathrm{L} / \mathrm{h}$. All of the tests were conducted at $22{ }^{\circ} \mathrm{C}$ with the relative humidity level controlled at $65 \pm 1 \%$.

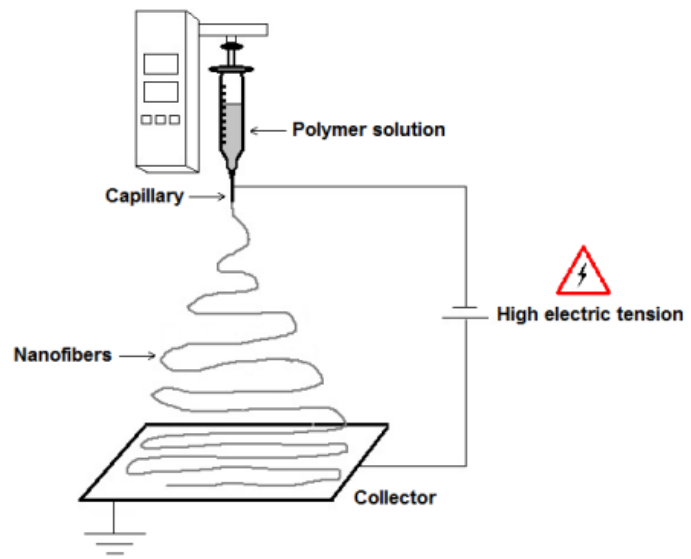

Figure 1: Schematic diagram of the electrospinning process.

\subsection{Shape and diameter of the nanofibers}

Images and 30 measurements of the diameters of the nanofibers were obtained using a scanning electron microscope (SEM) (JEOL JSM-6610 LV, Japan). Before the analyses, the samples were fixed in a metallic holder with carbon tape and coated with gold using a sputtering diode (Denton Vacuum 111 CAR001-0038, USA).

\subsection{Statistical Analysis}

The results were evaluated by analysis of variance (ANOVA) and Tukey test to compare the means of the 
studied response, with a significance level of $99 \%(\mathrm{p} \leq 0,01)$.

\section{RESULTS AND DISCUSSION}

In the electrospinning technique, the following parameters that had been determined in preliminary tests were used: distance from the capillary to the collector of $140 \mathrm{~mm}$ and solution feed rate of $500 \mu \mathrm{L} / \mathrm{h}$. The process parameters, capillary diameter and the electric potential were evaluated on the conditions shown in Table 1.

Table 1: Results of variation the parameters of the electrospinning process.

\begin{tabular}{ccc}
\hline Capillary (mm) & Electric potential $\mathbf{( k V )}$ & Diameter $(\mathbf{n m})$ \\
\hline 0.45 & 15 & $556 \pm 120^{\mathrm{bc}}$ \\
& 20 & $501 \pm 156^{\mathrm{abc}}$ \\
& 25 & $472 \pm 120^{\mathrm{ab}}$ \\
& 15 & $364 \pm 63^{\mathrm{a}}$ \\
0.55 & 20 & $376 \pm 71^{\mathrm{a}}$ \\
& 25 & $415 \pm 80^{\mathrm{ab}}$ \\
& & \\
& 15 & $409 \pm 91^{\mathrm{ab}}$ \\
& 20 & $780 \pm 202^{\mathrm{de}}$ \\
& 25 & $806 \pm 399^{\mathrm{e}}$ \\
& & \\
& 15 & $966 \pm 262^{\mathrm{f}}$ \\
& 20 & $716 \pm 210^{\mathrm{de}}$ \\
& 25 & $646 \pm 170^{\mathrm{cd}}$ \\
\hline
\end{tabular}

The same letters in the column indicate that the results did not differ significantly with $95 \%$ confidence level.

In accordance with RAMAKRISHNA, et al. [9], the effect of the electrospinning process, with the PAN polymer and solvent DMF, the dimensions of the nanofibers results in production of continuous nanofibers with diameters of up to $1000 \mathrm{~nm}$. BARHATE, et al. [10] have obtained porous nanofibers with the PAN polymer $(\mathrm{Mw}=150,000)$ of $500 \mathrm{~nm}$ by electrospinning method. The large surface area of these structures provides nanofibers with high pore volume and different sizes.

These pores facilitate bioactive molecules loading and transport of nutrients and waste, and allow the polymer nanofibers become important class of biomaterials [11]. Under suitable conditions, uniform and defect-free nanofibers are deposited on the collector. Dynamic interactions between polymer chains, such as entanglement, hydrophobic interaction and hydrogen bonding, are essential for reducing the fiber diameter to the nanoscale level and maintaining continuous fiber formation [12].

In this study, the lowest average diameter of the nanofibers obtained was $364 \pm 63 \mathrm{~nm}$, with 10\% concentration of polymer solution PAN / DMF, electric potential of $15 \mathrm{kV}$ and capillary diameter of $0.55 \mathrm{~mm}$, with no significant difference $(\mathrm{p}<005)$ to the results obtained with the capillaries of 0.45 to $0.55 \mathrm{~mm}$. According RAMAKRISHNA, et al. [9] the reduction of the capillary diameter decreases the diameter of the nanofibers, as can be seen in the results of Table 1 into the capillaries of 0.45 to $0.55 \mathrm{~mm}$.

The small diameter also reduces the occurrence of clogging of the capillary, due to the lower exposure of the solution at ambient atmosphere during the electrospinning process [9]. According to the SHIN, et al. [13], obtaining fibers with reduced diameter is important for promoting the stability of the jet during electrospinning.

The solution concentration is the most important parameter to affect the nanofiber diameter. Lower solution concentration produces finer nanofiber diameters but at the same time supports bead formation. On the other side, raising the concentration increases the diameter [14]. Generally, the high molecular weight polymer is used in electrospinning, because they provide the desired viscosity for fiber production [8]. The 
polymer solution at $10 \%$ exhibited sufficiently high concentration and viscosity $(346,9 \mathrm{mPa} . \mathrm{s})$ to produce uniform nanofibers.

REN, et al. [15] have obtained nanofibers with diameter smaller $(480 \pm 58 \mathrm{~nm})$ with $10 \%$ polymer solution PAN with DMF. GU, et al. [16] have obtained nanofibers with diameters between 130 and $280 \mathrm{~nm}$ with $10 \%$ of the same solution. According KIRECCI, et al. [14] the best nanofibers (without formation of beads) can be obtained with a $10 \%$ solution concentration.

Figure 2 shows SEM images of the morphological structure of nanofibres, which presented morphologies (without beads), continuous and three dimensional structure.

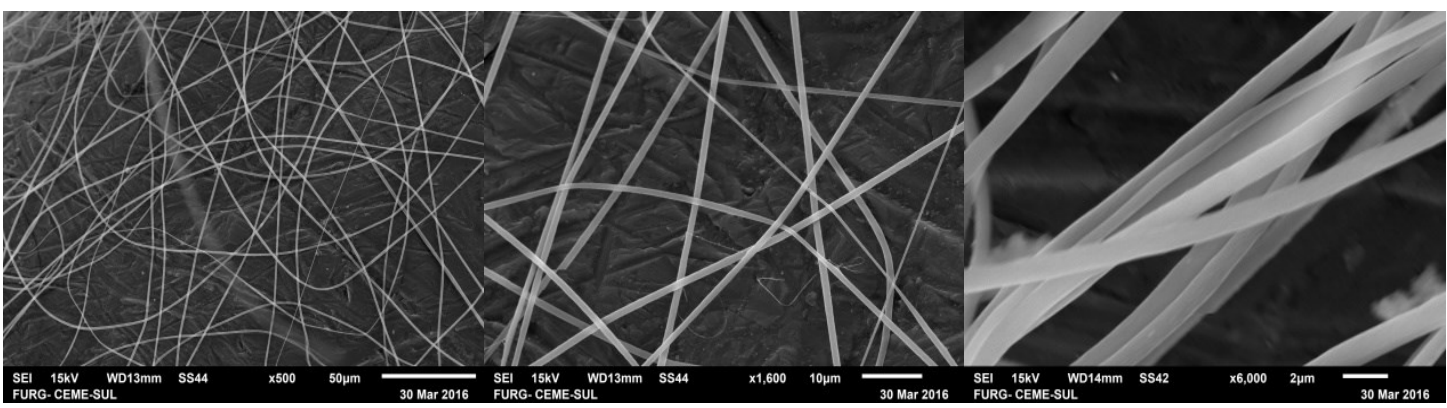

(a)

(b)

(c)

Figure 2: SEM images of nanofibers surface 10\% PAN with DMF (a) image magnification 500x (b) 1600x and (c) $6000 x$.

The variation of electrical potential as a function of capillary 0.45 and $0.55 \mathrm{~mm}$, did not influence the size of the nanofibers $(\mathrm{p}<0.05)$ (Table 1$)$. In these conditions were obtained uniform nanofibers and continuous (Fig. 2). With the $0.70 \mathrm{~mm}$ capillary, the increased electric potential increased diameter of nanofibres, because of the formation of beads under these conditions. This may have occurred due to larger amount of polymer solution exiting from the capillary, and not evaporation of the solvent until deposition on the collector. According BHARDWAJ and KUNDU [8], with higher potential is most likely the granule formation.

With the capillary of $0.80 \mathrm{~mm}$, the increase of electric potential reduced the diameter and were obtained uniform and continuous nanofibers (Fig. 2). In the electrospinning process a crucial element is the applied voltage to the solution. There is an ideal range of applied voltage or electric field intensity for a given polymer-solvent system, wherein the nanofiber formation is desirable [17]. The increase in the applied voltage, i.e., by increasing the electric field strength, increases the electrostatic repulsive force on the fluid jet which ultimately favours the narrowing of fiber diameter.

In most cases, a higher voltage causes greater stretching of the solution due to the greater columbic forces in the jet as well as a stronger electric field. Thus, voltage influences fiber diameter, but the level of significance varies with the polymer solution concentration and on the distance between the tip and the collector $[8,18]$.

\section{CONCLUSIONS}

Polymer nanofibers PAN with DMF $(10 \% \mathrm{w} / \mathrm{v})$ were produced by different conditions of the electrospinning process. Through the variation the process parameters was obtained nanofibers with different sizes and shape. Nanofibers continuous, uniforms and with reduced diameter were obtained with the diameters of the capillary of $0.45 \mathrm{~mm}(472 \pm 120 \mathrm{~nm})$ and $0,55 \mathrm{~mm}(364 \pm 63 \mathrm{~nm})$, differing statistically from the others results obtained with capillary diameters of 0,70 and $0.80 \mathrm{~mm}$. Thus, the manipulation of electrospinning parameters results in nanofibers with high surface area relative to volume, with the potential to significantly improve the current technology and find applications in new areas.

\section{ACKNOWLEDGMENTS}

The authors are grateful to CAPES (Coordination for the Improvement of Higher Education Personnel), CNPq (National Council of Technological and Scientific Development), CGTEE (Company of Thermal Generation of Electric Power), CEME-SUL (Electron Microscopy Center of South) and MCTI (Ministry of Science Technology and Innovation) for the financial support that made this research possible. 


\section{BIBLIOGRAPHY}

[1] ASSIS, L., ZAVAREZE, E. R., PRENTICE-HERNÁNDEZ, C., et al.," Review : Characteristics of nanoparticles and their potential applications in foods", Brazilian Journal of Food Technology, v. 15, n. 2, p. 99 109, Apr. 2012.

[2] THAVASI, V., SINGH, G., RAMAKRISHNA, S., "Electrospun nanofibers in energy and environmental applications", Energy \& Environmental Science, v.1, pp. 205-221, 2008.

[3] DING, B., YU, J., Electrospun nanofibers for energy and environmental applications. [s.1.], SpringerVerlag Berlin Heidelberg, 2014.

[4] WEISS, J., TAKHISTOV, P., MCCLEMENTS, D.J., "Functional Materials in Food Nanotechnology", Journal of Food Science, v. 71, n.9, pp. 107-116, Nov. 2006.

[5] SCHMATZ, D.A., UEBEL, L.S., KUNTZLER, S.G., et a.l, "Scaffolds containing Spirulina sp. LEB 18 biomass: development, characterization and evaluation of in vitro biodegradation", Journal of Nanoscience and Nanotechnology, v. 15, pp. 1-10, Jan. 2016.

[6] BAJI, A., MAI, Y-M., WONG, S-C., et al., "Electrospinning of polymer nanofibers: Effects on oriented morphology, structures and tensile properties", Composites Science and Technology, v. 70, n.5, pp. 703-718, May. 2010.

[7] MORAIS, M.G., VAZ, B.S., MORAIS, E.G., et al., "Biological Effects of Spirulina (Arthrospira) Biopolymers and Biomass in the Development of Nanostructured Scaffolds", Biomed Research International, v. 2014, pp. 1-9, Jul. 2014.

[8] BHARDWAJ, N., KUNDU, S.C., "Electrospinning: A fascinating fiber fabrication technique", Biotechnology Advances, v. 28, n.3, pp. 325-347, Jun. 2010.

[9] RAMAKRISHNA, S., FUJIHARA, K., TEO, W-E., et al., An Introduction to Electrospinning and Nanofibers, World Scientific Publishing, Singapore, 2005.

[10] BARHATE, R.S., LOONG, C.K., RAMAKRISHNA, S.R., "Preparation and characterization of nanofibrous filtering media”, Journal of Membrane Science, v. 283, n.1-2, pp. 209-218, Oct. 2006.

[11] KAI, D., LIOW, S. S., LOH, X. J. "Biodegradable polymers for electrospinning: Towards biomedical applications", Materials Science and Engineering: C, v. 45, n.1, pp. 659-670, Dec. 2014.

[12] TERADA, D., KOBAYASHI, H., ZHANG, K., et al., "Transient charge-masking effect of applied voltage on electrospinning of pure chitosan nanofibers from aqueous solutions", Science and Technology Advanced Materials, v. 13, n.1, pp. 015003, Feb. 2012.

[13] SHIN, Y.M., HOHMAN, M.M., BRENNER, M.P., et al., "Experimental characterization of electrospinning: the electrically forced jet and instabilities", Polymer, v. 42, n.5, pp. 09955-09967, Dec. 2001.

[14] KIRECCI, A., OZKOÇ, U., IÇOGLU, H.I., "Determination of Optimal Production Parameters for Polyacrylonitrile Nanofibers", Journal of Applied Polymer Science, v. 124, n.6, pp. 4961-4968, Jun. 2012.

[15] REN, C., PAN nanofibers and nanofiber reinforced composites, Mechanical (and Materials) Engineering, Degree Ph.D., University of Nebraska-Lincoln, 2013.

[16] GU, S.Y., REN, J., WU, Q.L., "Preparation and structures of electrospun PAN nanofibers as a precursor of carbon nanofibers", Synthetic Metals, v. 155, n.1, pp. 157-161, Oct. 2005.

[17] PILLAY, V., DOTT, C., CHOONARA, Y.E., et al., "A Review of the Effect of Processing Variables on the Fabrication of Electrospun Nanofibers for Drug Delivery Applications", Journal of Nanomaterials, v. 2013, 1-22, Dec. 2013.

[18] YORDEM, O.S., PAPILA, M., MENCELOĞLU, Y.Z., "Effects of electrospinning parameters on polyacrylonitrile nanofiber diameter: an investigation by response surface methodology", Materials and Design, v. 29, n.1, pp. 34-44, Jan. 2008. 